\title{
Antineuron specific enolase staining reactions in sarcomas and carcinomas: its lack of neuroendocrine specificity
}

\author{
MARY LEADER, M COLLINS, J PATEL, KRISTIN HENRY \\ From the Department of Histopathology, Westminster and Charing Cross Medical School, London
}

SUMMARY A commercially available polyclonal antiserum (Dakopatts) raised against bovine neuron specific enolase (NSE) was reacted with 197 sarcomas, 32 carcinomas, 11 carcinoid tumours and 20 malignant melanomas to assess its specificity for neuroendocrine tumours. All the tumours had been fixed in formalin and embedded in paraffin. Positive tumour cells were found in two of 11 squamous cell carcinomas, one of 11 adenocarcinomas, 10 of 10 oat cell carcinomas, 11 of 11 carcinoid tumours, 16 of 20 malignant melanomas, four of seven clear cell sarcomas, nine of 25 leiomyosarcomas, four of 22 rhabdomyosarcomas, one of seven angiosarcomas and one of 20 synovial sarcomas.

Neuron specific enolase (NSE) $(\gamma \gamma)$ is an isoenzyme of the glycolytic enzyme enolase. ${ }^{1}$ It was first localised in neurones but was subsequently found in neuroendocrine derived cells throughout the body. ${ }^{23}$ The antibodies raised against this antigen are widely used as tumour markers of neuroendocrine derived neoplasms. Although certainly useful in this respect, no study has adequately examined the specificity of commercially available NSE antibodies for neuroendocrine tumours. This information is obviously essential if NSE is to be used as a reliable tumour marker. As staining for NSE using the immunocytochemical peroxidase-antiperoxidase (PAP) method can be technically quite difficult and as the reagents are expensive, it is important that the optimal staining methods are well documented and the pitfalls associated with using this reagent well publicised. With these factors in mind, this study examined 32 carcinomas, 11 carcinoid tumours, 20 malignant melanomas and 197 sarcomas using a polyclonal commercially available antibody (Dakopatts) to NSE. All tumours studied had been fixed in formalin and embedded in paraffin.

\section{Material and methods}

Thirty two carcinomas, 11 carcinoid tumours, 20 malignant melanomas and 197 sarcomas were included in this study. All were fixed in neutral buffered formalin and all were embedded in paraffin. The sarcomas were obtained from the files of this hospital. The age of the blocks ranged from 1-28 years. All sarcomas were examined by Professor DH MacKenzie. ${ }^{4}$ These were diagnosed mainly on the basis of haematoxylin and eosin staining and nonimmunocytochemical special stains. In "difficult" tumours and where material was available electron microscopy was carried out. The remaining tumours were chosen retrospectively from the files of this hospital and ranged in age from 1-4 years.

NSE antiserum (Dakopatts) consists of polyclonal antibodies raised against bovine NSE. Its reliability was initially tested on a series of positive controls (nerve bundles). The reagent was also tested at differing dilutions and at varying temperatures and on sections which had and had not been trypsinised. The staining procedure used was the peroxidaseantiperoxidase technique. The best and most reliable results were obtained without trypsinisation, using a dilution of $1 / 4000$ with overnight incubation and continuous agitation. Good results, however, were also obtained using a dilution of $1 / 400$ with one hour of incubation. As the former method gave optimal results and it was considerably less expensive, this was the procedure used:

1 Dewax $4 \mu \mathrm{m}$ and $5 \mu \mathrm{m}$ sections and take to absolute alcohol.

2 Immerse in $3 \% \mathrm{H}_{2} \mathrm{O}_{2}$ in $\mathrm{MeOH}$ for 20 minutes to quench endogenous peroxidase. 
3 Hydrate and rinse in $0.05 \mathrm{M}$ Tris buffered saline (TBS).

4 Apply normal swine serum (NSS) diluted $1 / 5$ with TBS for 20 minutes to prevent non-specific background staining.

5 Tip off NSS and wipe around sections.

6 Apply anti-NSE (Dakopatts) diluted 1/4000 with TBS and incubate overnight at room temperature with gentle agitation.

7 Rinse with TBS and wash in three changes of TBS for 10 minutes.

8 Wipe around sections and apply the $2^{\circ} \mathrm{C}$ antibody swine antirabbit immunoglobulin (Dako Z196) diluted 1/50 with TBS for 30 minutes at room temperature with gentle agitation.

9 Rinse with TBS and wash in three changes of TBS for 10 minutes.

10 Wipe around sections and apply the peroxidaseantiperoxidase (Dako, rabbit, Z113) diluted 1/50 with TBS for 30 minutes at room temperature with gentle agitation.

11 Rinse with TBS and wash in three changes of TBS for 10 minutes.

12 Incubate for 10 minutes at room temperature with gentle agitation with diaminobenzidine (DAB) solution $(6 \mathrm{mg}$ of 3,3 diaminobenzidine tetrahydrochloride dissolved in $10 \mathrm{ml}$ of $0.05 \mathrm{M}$ Tris buffered saline). Filter and add $0.1 \mathrm{ml}$ of $3 \% \mathrm{H}_{2} \mathrm{O}_{2}$ immediately before use.

13 Wash thoroughly with running tap water and counterstain with haematoxylin.

14 Dehydrate, clear, and mount.

Each tumour was coded with a case number from 1-260. Twenty to $304 \mu \mathrm{m}$ or $5 \mu \mathrm{m}$ sections were cut from each block and one stained with anti-NSE, as described above. Sections were reacted in batches of 20 to 30 . Each batch included the following controls: a positive control (nerve bundles); a negative control where the primary antibody was deleted; and a control section where $\mathrm{H}_{2} \mathrm{O}_{2}$ and methanol were omitted to check endogenous peroxidase activity. In the initial batches a further negative control where the secondary antibody was deleted was also included.

We were unable to use preadsorbed antiserum as a control as we did not have the appropriate facilities, but as the purpose of the study was specifically to document the range of positivity of a commercial anti-NSE this did not invalidate the results.

Each coded section was examined using a $\times 4$, $\times 10$, and $\times 40$ objective on each section. A positive or negative result was reported in the absence of the haematoxylin and eosin diagnosis. Only the presence of discrete cytoplasmic staining was accepted as a positive result. The case numbers were then decoded and the result of the staining tabulated against each tumour.
SPECIAL NOTES ON THE STAINING METHOD

USING NSE ANTISERUM

1 Slides may be coated or uncoated. Slides must, however, be placed on a hot plate until the paraffin wax surrounding the sections begins to melt and they must then be removed to an incubator $\left(37^{\circ} \mathrm{C}\right)$ for a minimum of one night.

2 Sections with melanin require the following special treatment:

(i) Coating of slides is imperative.

(ii) Melt wax as described above.

(iii) Bleach melanin. After quenching the endogenous peroxidase and hydration, but before normal swine serum, bleach in $1 \%$ potassium permanganate followed, after washing, by $1 \%$ oxalic acid. Wash thoroughly. Times will depend on the amount of melanin and will, presumably, be known from routine haematoxylin and eosin staining.

(iv) Incubate with anti-NSE at 1/400 for one hour at room temperature with gentle agitation and with $2^{\circ} \mathrm{C}$ and $3^{\circ} \mathrm{C}$ at $1 / 100$ for 30 minutes with agitation and the usual washes. Use DAB as usual for 10 minutes.

3 The shortened incubation time for sections containing melanin is to reduce the risk of the sections floating off or disintegrating after bleaching. It may, of course, also be used where a speedy result is required.

4 On some sections there is a heavy brown deposit, probably of DAB. We tried unsuccessfully to exclude this by centrifugation and by varying the $\mathrm{pH}$ of the TBS from $7 \cdot 4$ to $7 \cdot 8$. It does seem to be reduced, however, by using a DAB solution that has been aliqoted and stored at $-20^{\circ} \mathrm{C}$.

5 Staining of sections seems to be more intense at the edges than in the interior. This may be due to cutting damage; it is reduced by using agitation during incubation.

6 More recent batches of NSE antiserum available from Dakopatts, require lower dilutions of anti-NSE than used in this study.

\section{Results}

Thirty two carcinomas, 11 carcinoid tumours, 20 malignant melanomas and 197 sarcomas were stained with anti-NSE. Tables 1 and 2 summarise the results. Normal eccrine glands, smooth muscle, and skeletal muscle included in many of the sections stained positively. Occasional histiocytes within the sinuses of reactive nodes stained positively, as did the respiratory mucosa lining and bronchi.

CARCINOMAS, CARCINOID TUMOURS, AND

MALIGNANT MELANOMAS (TABLE 1)

Two of 10 squamous cell carcinomas stained posi- 
Table 1 Anti-NSE staining of 63 carcinomas

\begin{tabular}{llrr}
\hline Tumours & Sites & No & Positive \\
\hline Squamous cell carcinomas & Lung, cervix, larynx, cheek, & 10 & \\
oesophagus & Cervix, lung, prostate, kidney, & 11 & 2 \\
Adenocarcinomas & endometrium & 1 & 1 \\
Transitional cell carcinomas & Bladder & 10 & 0 \\
Oat cell carcinomas & Lung & 20 & 10 \\
Malignant melanomas & Skin & 11 & 16 \\
Carcinoid tumours & Appendix, small intestine & 4 \\
\hline
\end{tabular}

Table 2 Anti-NSE staining of 197 sarcomas

\begin{tabular}{lrlr}
\hline Tumours & No & Positive & Negative \\
\hline Clear cell sarcomas & 7 & 4 & 3 \\
Synovial sarcomas & 20 & 1 & 19 \\
Leiomyosarcomas & 25 & 9 & 16 \\
Fibrosarcomas & 20 & 0 & 20 \\
Rhabdomyosarcomas & 22 & 4 & 18 \\
Malignant fibrous histiocytomas & 27 & 0 & 27 \\
Malignant neural tumours & 18 & 0 & 18 \\
Liposarcomas & 21 & 0 & 21 \\
Kaposi's sarcomas & 9 & 0 & 9 \\
Haemangiopericytomas & 18 & 0 & 18 \\
Angiosarcomas & 7 & 1 & 6 \\
Sarcomas (unclassified) & 3 & 0 & 3 \\
\hline
\end{tabular}

tively with NSE antiserum. Both were oesophageal tumours. One of 11 adenocarcinomas stained positively: the positive result was in a well differentiated adenocarcinoma of the endometrium. Weak, diffuse, and granular cytoplasmic staining was seen especially at the apical border of the glandular epithelium. All 10 oat cell carcinomas stained positively (fig 1 ). In many tumours only a few cells stained, and in many cases these were cells either lying singly or occurring towards the periphery of the tumour, rather than cells forming large sheets of tumour. A similar staining pattern has been noted by others (Springall DR, Ibrahim NBN, Polak JAA, Pathology Society of Great

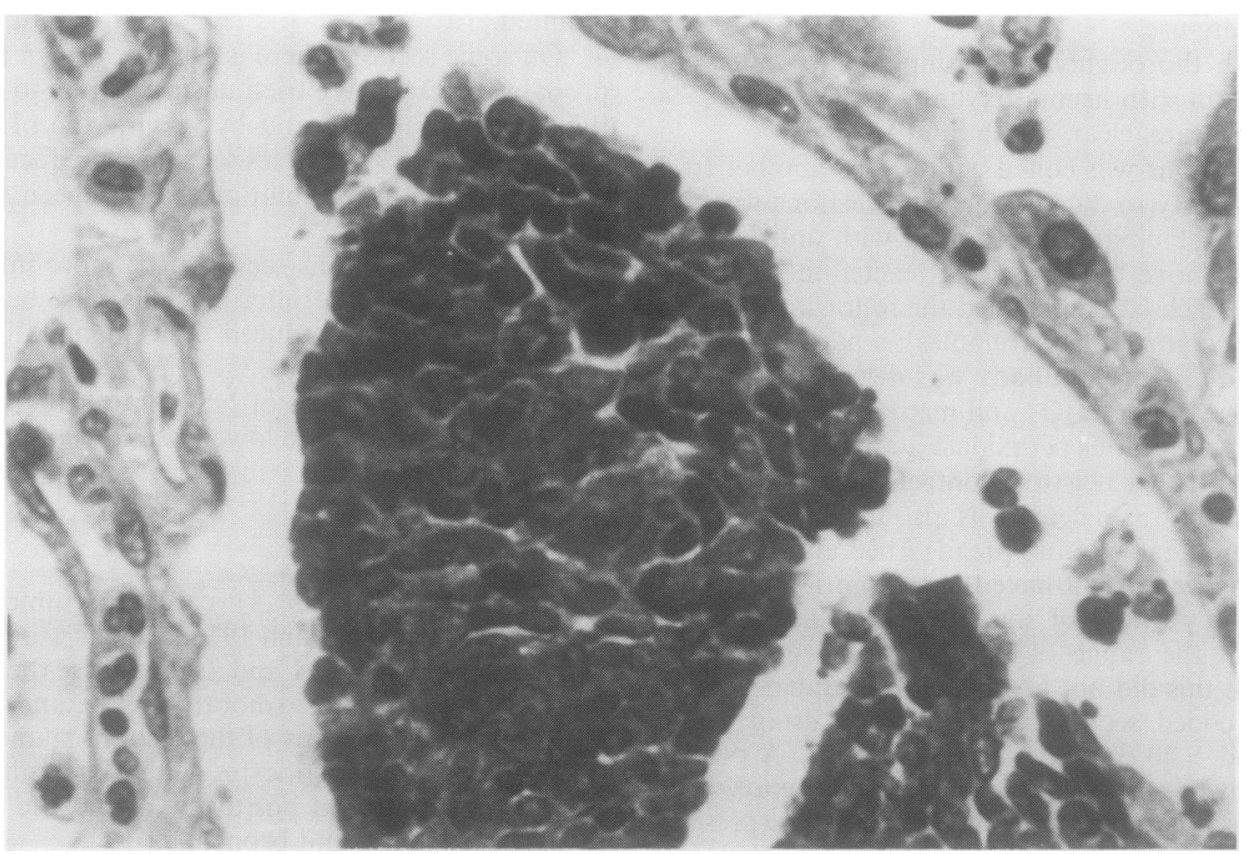

Fig 1 Oat cell carcinoma within alveolar space. Many positively stained tumour cells are seen. (Anti-NSE.) $\times 400$. 


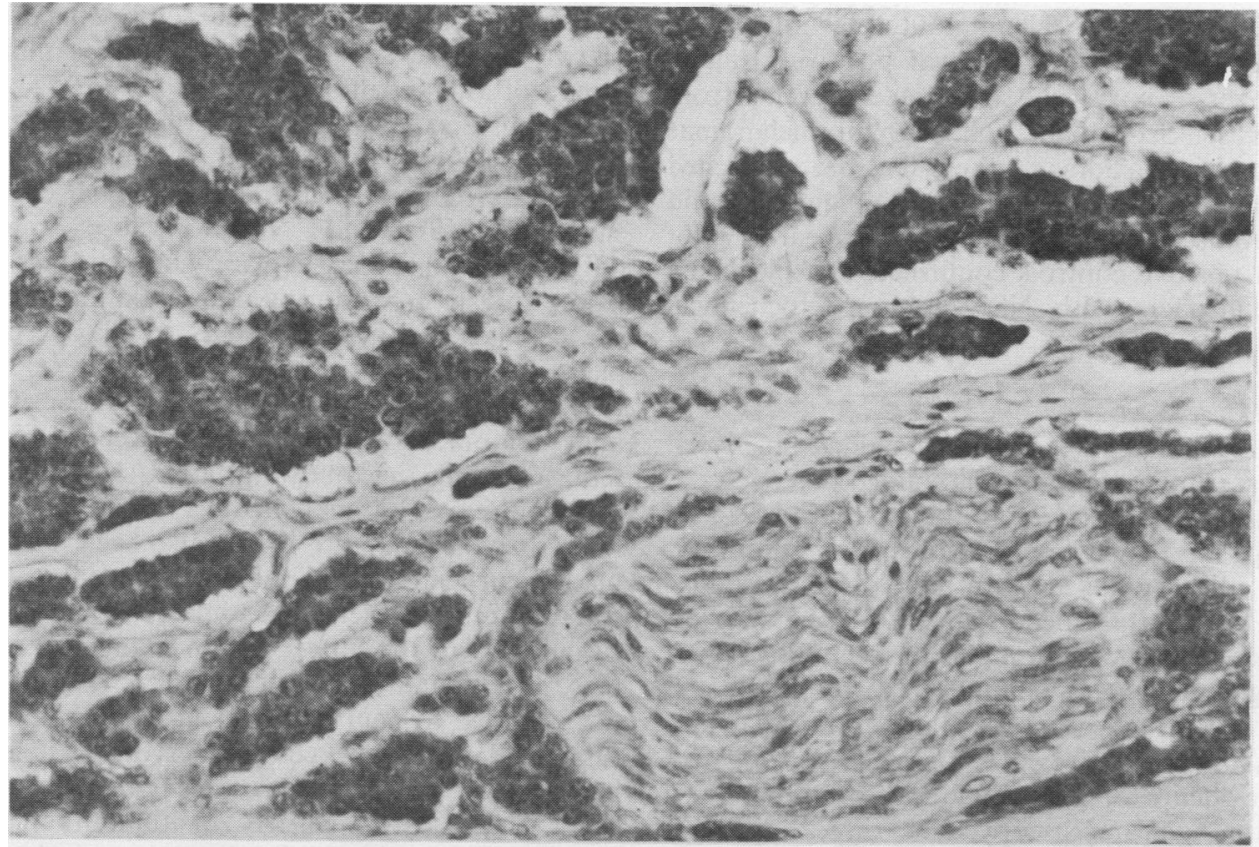

Fig 2 Carcinoid tumour of appendix. Cytoplasm of tumour cells shows granular staining. Staining of nearby nerve is also seen. (Anti-NSE.) $\times 400$.

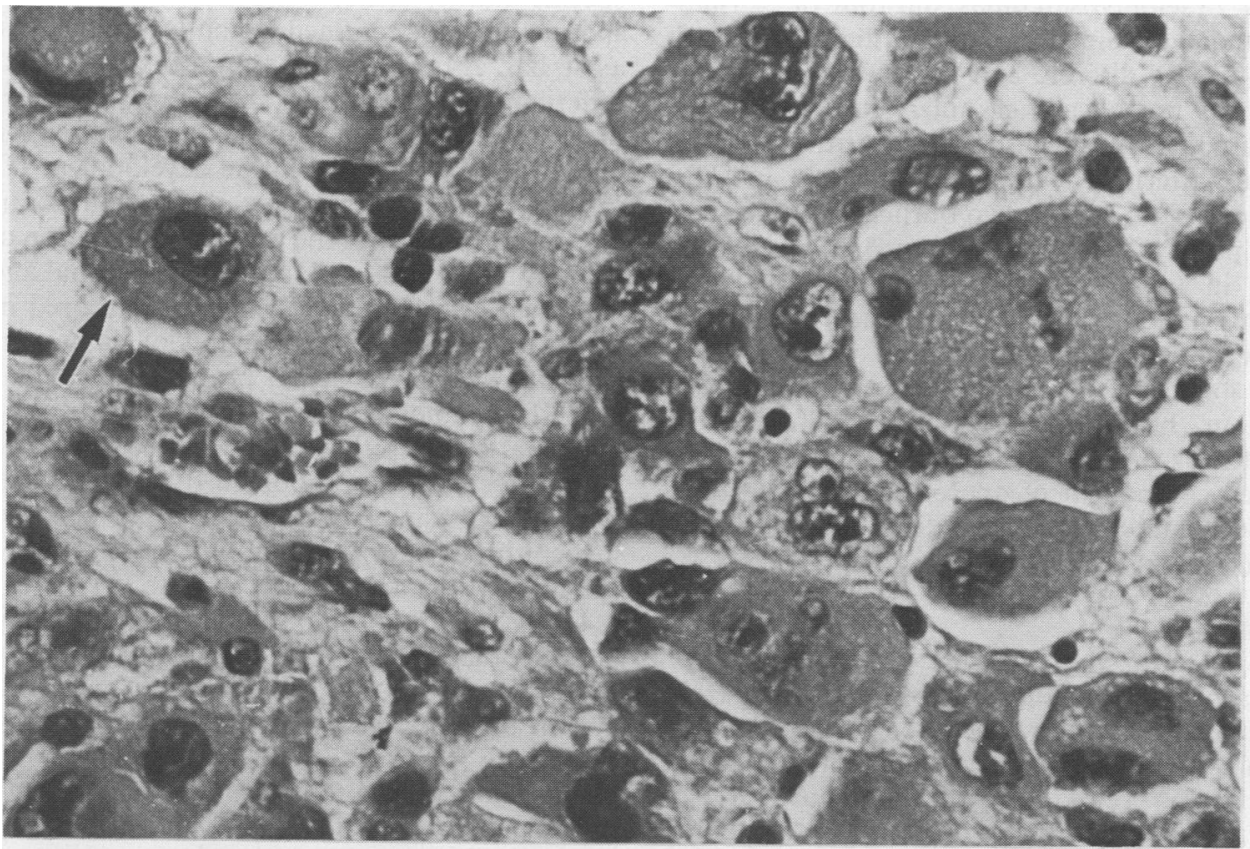

Fig 3 Pleomorphic rhabdomyosarcoma. Tumour cells with cross striations (not shown) were seen. Many large pleomorphic tumour cells (arrow) stained strongly with anti-NSE. (Anti-NSE.) $\times 800$. 
Britain and Northern Ireland, 150th meeting, 1985). All 11 carcinoid tumours stained positively (fig 2). The number of positively staining cells varied from case to case. Sixteen of 20 malignant melanomas stained positively. Some of these had been bleached before staining with anti-NSE so that pigment would not be confused with a positive result. An earlier pilot study on positive controls confirmed that bleaching did not interfere with NSE immunocytochemical staining.

\section{SAR COMAS (TABLE 2)}

Four of seven clear cell sarcomas stained positively. In two cases most tumour cells stained positively. In the remaining two cases the staining pattern was curious: the positive areas were seen as sheets of positively staining cells, admixed with cytologically similar sheets of cells that stained negatively, giving an overall streaky pattern of staining to the sections. At first we thought this type of staining pattern might be an artefact, but on repeating the staining a similar pattern was obtained on two further occasions. There was no evidence of pigment in either of these two cases with light microscopy. The three negatively staining clear cell sarcomas were classical examples of this type of tumour and on reviewing their sections we were in no doubt that the diagnosis was correct. The NSE staining was repeated and all again showed negative staining.

Nine of 25 leiomyosarcomas and four of 22 rhabdomyosarcomas stained positively (fig 3 ). Although the staining was discrete and confined to the cytoplasm it was not always granular. In many of the leiomyosarcomas most cells stained positively, but in others the pattern of staining was uneven and was reminiscent of that seen in two of the clear cell sarcomas. The positive rhabdomyosarcomas showed cross striations in two cases. The remaining two were embryonal rhabdomyosarcomas. A large number of tumour cells in all cases stained. One of seven angiosarcomas stained positively. The endothelial nature of this tumour had previously been confirmed by positive factor VIII related antigen staining. The spindle cell component of one of 20 synovial sarcomas stained positively; the "glandular" component in all stained negatively.

\section{Discussion}

Enolase isoenzymes are dimeric proteins formed from three subunits, $\alpha, \beta$, and $\gamma$. The isoenzyme $\alpha \alpha$ is found mainly in liver and the isoenzyme $\beta \beta$ mainly in skeletal muscle. In brain, however, a mixture of isoenzymes is found: neuron specific enolase (NSE) $\gamma \gamma$, non-neuronal enolase (NNE) $\alpha \alpha$; and the hybrid enolase $\alpha \gamma \cdot{ }^{56}$ NSE was so named because initially it was found only in neurones. ${ }^{7}$ It is a protein consisting of two identical subunits, each having a molecular weight of 39000 daltons. ${ }^{89}$

It seems that NNE $(\alpha \alpha)$ is the dominant enzyme in fetal brain ${ }^{10-12}$ and that NSE $(\gamma \gamma)$ may be a marker of neural differentiation. ${ }^{5}$ The functional characteristics of NSE and NNE disclose important differences, ${ }^{13}$ and may explain why neurones switch from NNE to NSE during differentiation ${ }^{5}$ and why the cellular specificity of NSE is relaxed in neoplasia. $^{14}$

NSE has been identified in a large number of tissues and tumours derived from the neuroendocrine system, including the following: apud cells of the thyroid, pituitary, adrenal medulla, pancreatic islets, ${ }^{2}$ lung, ${ }^{15}$ skin $^{16}$ and gut. ${ }^{7}$ It has also been localised in many neuroendocrine tumours, ${ }^{17}$ in pancreatic islet cell tumours, ${ }^{18}$ in neuroblastomas, ${ }^{19-21}$ in small cell carcinomas of the lung, ${ }^{22-24}$ in malignant melanomas, ${ }^{2526}$ and in Merkel cell tumours. ${ }^{27}$ Its presence is not confined to neuronal or neuroendocrine derived tumours. Within the central nervous system NSE has been detected in astrocytes ${ }^{20} 28$ and has also been detected in a variety of tumours including astrocytomas, oligodendrogliomas, ependymomas, pineocytomas, meningiomas, choroid plexus papillomas, ${ }^{20}$ medulloblastomas ${ }^{1920}$ and retinoblastomas. ${ }^{19}$

The results of this study show that NSE is not a specific marker of neuroendocrine cells. This lack of specificity is not confined to the Dakopatts antibody as it has also been found by other workers using differing sources of antibody. Haimoto et al, ${ }^{29}$ who have made important advances in the isolation of enolase isoenzymes and in the development of sensitive and specific assays for the various brain isoenzymes, reported on the immunolocalisation of the $\gamma$ subunit in cell classes that are non-neuronal and nonendocrine. Having reacted antibodies raised in their laboratory against the $\gamma$ subunit of human enolase, they reported positivity in bronchial epithelial cells, type II pneumocytes, pancreatic and parotid ductal epithelial cells, epithelial cells of the loop of Henle, secretory cells of the fallopian tube, bile ducts, lymphocytes, plasma cells, platelets, megakaryocytes, myoepithelial cells and smooth muscle cells of the uterus and various arteries.

Using an anti-NSE antibody prepared by Marangos, other workers have shown the presence of NSE in epithelial cells of the loop of Henle, ${ }^{20}$ carcinomas of the ovary, ${ }^{30}$ breast carcinomas, ${ }^{20}{ }^{30}$ the only case of fibrocystic disease of the breast examined, two fibroadenomas, two renal cell carcinomas, within the follicular cells of nodular goitre, in a giant cell tumour of tendon sheath, and within a large number of physaliferous cells of a chordoma. ${ }^{20}$ Using Marangos' 
antibody and also a Polysciences antibody, diffuse cytoplasmic staining has been described in three of six lymphomas and in one rhabdomyosarcoma. ${ }^{21}$ Marangos has also reported the presence of NSE in small amounts of erythrocytes and platelets. ${ }^{31}$

The specificity of the $\gamma$ subunit of enolase has been discussed. ${ }^{32}$ The conclusion reached is that it is neither non-specific nor neuron specific. A review of published reports on the subject provides scanty information regarding the staining reactions of NSE antiserum and mesenchymal tumours. A leiomyoma of the uterus and a rhabdomyosarcoma described by Vinores et al (Marangos antibody) ${ }^{20}$ stained negatively with anti-NSE, while one of three Schwannomas stained positively. Tsokos et $\mathrm{al}^{21}$ (Marangos antibody and Polysciences antibody) examined 10 soft tissue sarcomas of unspecified type. One embryonal rhabdomyosarcoma showed positive staining but only of the differentiated rhabdomyoblasts. This finding contrasts with that of the positively staining rhabdomyosarcomas in our study, where large pleomorphic tumour cells also stained positively.

The positive staining of clear cell sarcomas in this study is to be expected if one accepts that these tumours are the soft tissue counterpart of malignant melanomas. Such a histogenesis has been advanced by Chung and Enzinger. ${ }^{33}$ Electron microscopy also supports this view as melanosomes have been shown at ultrastructural level. ${ }^{34}$ The positive staining of leiomyosarcomas and rhabdomyosarcomas is not unexpected bearing in mind that enolase has three distinct subunits-liver $(\alpha)$, muscle $(\beta)$, and neuron specific $(\gamma){ }^{5}$ Cross reactions between these subunits when using NSE antiserum presumably explains the common staining of normal smooth muscle and skeletal muscle. ${ }^{21}$

The positive staining of the angiosarcoma in this study is puzzling. Under normal circumstances endothelial cells do not stain positively for NSE, although Dhillon and Rode ${ }^{35}$ state that overincubation with substrate may produce staining of blood vessels. It is possible, therefore, that the positive staining represents a false positive result. As for the positive staining of the biphasic synovial sarcoma, this again may suggest a false positive result. The tumour had not previously been irradiated. Some workers, however, might argue that a positive NSE staining pattern in a synovial sarcoma lends support to the concept that synovial sarcomas are closely related to clear cell sarcomas. $^{36}$

Other workers have compared NSE antiserum from varying sources, using different staining techniques. Tsokos et al ${ }^{21}$ compared the commercially available Polysciences antisera with that of Marangos' non-commercially available antisera and found that the Petrusky Ig-enzyme bridge method yielded the most reliable and consistent results among the immunocytochemical methods tested. They found Sternberger's PAP method was associated with a higher percentage of false positive results and with background staining. The Polysciences antisera showed variations both quantitatively and qualitatively among the same group of tumours under various conditions. Both antisera stained smooth and skeletal muscle and Marangos' anterisa to a lesser extent. They also compared the commercially available Polysciences antisera with bovine NSE available from Dakopatts. Their results suggested that bovine NSE was superior in terms of consistency, reliability, and low degree of cross reactivity. They found Petrusky's technique superior to Sternberger's PAP technique when using Polysciences antisera, but this was not the case when antisera obtained from Dako was used. ${ }^{21}$

Nuclear labelling with NSE antisera may also be found. Schmechel et $\mathrm{l}^{5}$ attributed such nuclear staining to poor fixation. Haan et $\mathbf{a l}^{\mathbf{2 8}}$ found nuclear staining most strong at a slightly acidic or neutral $\mathrm{pH}$. They found it less strong when the $\mathrm{pH}$ of a second fixative solution was 9.5 and absent when the $\mathrm{pH}$ was increased to 11 .

A small number of cases that were initially included in the study had to be withdrawn as nerve fibres, which were included in the blocks, consistently failed to stain with NSE antiserum despite the positive control sections in the same batch staining intensely. We were unable to determine the reasons for this, but it does highlight the technical difficulties entailed in the use of this antiserum.

In conclusion, NSE is not a specific marker for neuroendocrine tumours. If it is known with which tissues and tumours it will cross react, however, then NSE antiserum may be useful in confirming the diagnosis of carcinoid tumours, oat cell carcinomas, and malignant melanomas.

We are most grateful to Professor DH MacKenzie who very kindly allowed us full access to his collection of soft tissue sarcomas. Without his diagnostic expertise this unique collection of cases would not have been available to us and this study could not have taken place.

ML is in receipt of a grant from the North West Thames Area Health Authority and the Westminster Hospital Research Trust.

\section{References}

1 Marangos PJ, Zomzely-Neurath C. Determination and characterisation of neuron-specific protein (NSP) associated enolase activity. Biochem Biophys Res Commun 1976;68:1309-16.

2 Schmechel D, Marangos PJ, Brightman M. Neuron-specific 
enolase as a molecular marker for peripheral and central neuroendocrine cells. Nature 1978;276:834-6.

3 Sheppard MN, Kurian SS, Henzen-Logmans SC, et al. Neuronspecific enolase and S-100: new markers for delineating the innervation of the respiratory tract in man and other mammals. Thorax 1983;38:333-40.

4 MacKenzie DH. The differential diagnosis of fibroblastic tumours. Oxford: Blackwell Scientific Publications, 1970.

5 Schmechel DE, Brightman MW, Marangos PJ. Neurons switch from non-neuronal to neuron-specific enolase during differentiation. Brain Res 1980;190:195-214.

6 Heydorn WE, Creed GJ, Marangos PJ, Jacobowitz DM. Identification of neuron-specific enolase and non-neuronal enolase in human and rat brain on two-dimensional polyacrylamide gels. $J$ Neurochem 1985;44:201-9.

7 Bishop AE, Polak JM, Facer P, Ferri G-L, Marangos PJ, Pearse AGE. Neuron-specific enolase: a common marker for the endocrine cells and innervation of the gut and pancreas. Gastroenterology 1982;83:902-15.

8 Marangos PJ, Zomzely-Neurath C, Luk D, York C. Isolation and characterisation of the nervous system-specific protein 14-3-2 from rat brain. J Biol Chem 1975;250:1884-91.

9 Marangos PJ, Zis A, Clark R, Goodwin F. Neuronal, nonneuronal and hybrid forms of enolase in brain: structural, immunological and functional comparisons. Brain Res 1978;150:117-33.

10 Rider CC, Taylor CB. Evidence for a new form of enolase in rat brain. Biochem Biophys Res Commun 1975;66:814-20.

11 Zomzely-Neurath C, Keller A. Nervous system specific proteins of vertebrates. Neurochem Res 1977;2:353-77.

12 Marangos PJ, Schmechel DE, Parma AM, Goodwin FK. Development profile of neuron-specific (NSE) and non-neuronal (NNE) enolase. Brain Res 1980;190:185-93.

13 Marangos PJ, Parma AM, Goodwin FK. Functional properties of neuronal and glial isoenzymes of brain enolase. J Neurochem 1978;31:727-32.

14 Haglid K, Carlsson CA, Stavrou D. An immunological study of human brain tumours concerning the brain-specific proteins S-100 and 14-3-2. Acta Pathol 1973;24:187-96.

15 Wharton J, Polak JM, Cole GA, Marangos PJ, Pearse AG. Neuron-specific enolase as an immunocytochemical marker for the diffuse neuroendocrine system of the human foetal lung. J Histochem Cytochem 1981;29:1359-64.

16 Gu J, Polak JM, Van Noorden S, Pearse AGE, Marangos PJ, Azzopardi JG. Immunostaining of neuron-specific enolase as a diagnostic tool for Merkel cell tumours. Cancer 1983;52: 1039-43.

17 Tapia FJ, Polak JM, Barbosa AJA, et al. Neuron-specific enolase is produced by neuroendocrine tumours. Lancet 1981;1:808-11.

18 Lloyd RV, Warner TFCS, Mervak T, Wilson BS, Schmidt K. Immunohistochemical detection of chromogranin and neuronspecific enolase in pancreatic endocrine neoplasms. Am J Surg Pathol 1984;8:607-14

19 Beemer FA, Vlug AMC, Van Veelan CWM, Rijksen G, Staal GEJ. Isoenzyme pattern of enolase of childhood tumours. Cancer 1984;54:293-6.

20 Vinores SA, Bonnin JM, Rubinstein LJ, Marangos PJ. Immuno- histochemical demonstration of neuron-specific enolase in neoplasms of the CNS and other tissues. Arch Pathol Lab Med 1984;108:536-40.

21 Tsokos M, Linnoila RI, Chandra RS, Triche TJ. Neuron-specific enolase in the diagnosis of neuroblastoma and other small round cell tumours in children. Hum Pathol 1984;15:575-84.

22 Sheppard MN, Corrin B, Bennett MH, Marangos PJ, Bloom SR, Polak JM. Immunocytochemical localization of neuronspecific enolase in small cell carcinomas and carcinoid tumours of the lung. Histopathology 1984;8:171-81.

23 Springall GA, Lackie P, Levene MM, Marangos PJ, Polak JM. Immunostaining of neuron-specific enolase is a valuable aid to the cytological diagnosis of neuroendocrine tumours of the lung. J Pathol 1984;143:259-65.

24 Johnson DH, Marangos PJ, Forbes JT, et al. Potential utility of serum neuron-specific enolase levels in small cell carcinoma of the lung. Cancer Res 1984;44:5409-14.

25 Rode J, Dhillon AP. Neuron-specific enolase and S- 100 protein as possible prognostic indicators in melanoma. Histopathology 1984;8:1041-52.

26 Warner TFCS, Lloyd RV, Hafez GR, Angevine JM. Immunocytochemistry of neurotropic melanoma. Cancer 1984;53 254-7.

27 Gu J, Polak JM, Tapia FJ, Marangos PJ, Pearse AGE. Neuronspecific enolase in the Merkel cells of mammalian skin. Am J Pathol 1981;104:63-8.

28 Haan EA, Boss BD, Cowan WM. Production and characterization of monoclonal antibodies against the "brain-specific" proteins 14-3-2 and S-100. Proc Natl Acad Sci USA 1982; 79:7585-9.

29 Haimoto H, Takahashi Y, Koshikawa T, Nagura H, Kato K. Immunohistochemical localization of $\gamma$ enolase in normal human tissues other than nervous and neuroendocrine tissues. Lab Invest 1985;3:257-63.

30 Wick MR, Scheithauer BW, Kovacs K. Neuron-specific enolase in neuroendocrine tumours of the thymus, bronchus and skin Am J Clin Pathol 1983;29:703-7.

31 Marangos PJ, Campbell IC, Schmechel DE, Murphy DL Goodwin FK. Blood platelets contain a neuron-specific enolase subunit. $J$ Neurochem 1980;34:1254-8.

32 Schmechel DE. $\gamma$ subunit of the glycolytic enzyme enolase: non-specific or neurone specific? Lab Invest 1985;3:239-42.

33 Chung EB, Enzinger FM. Malignant melanoma of soft parts. A reassessment of clear cell sarcoma. Am J Surg Pathol 1983;7:405-13.

34 Hoffman GJ, Carter D. Clear cell sarcoma of tendons and aponeuroses with melanin. Arch Pathol 1973;95:22-5.

35 Dhillon AP, Rode J. Patterns of staining for neuron-specific enolase in benign and malignant melanocytic lesions of the skin. Diagn Histopathol 1982;5:169-74.

36 Hajdu SI. Pathology of soft tissue tumours. Philadelphia: Lea and Febiger, 1979:204-10.

Requests for reprints to: Dr Mary Leader, Department of Pathology, St Laurence's Hospital, North Brunswick Street, Dublin 7, Ireland. 